ORIGINAL ARTICLE

AFRICAN JOURNAL OF CLINICAL AND EXPERIMENTAL MICROBIOLOGY

MAY 2008 ISBN 1595-689X VOL 9 No 2

AJCEM/2008026/20814

-http://www.ajol.info/journals/ajcem

COPYRIGHT 2008

AFR. J. CLN. EXPER. MICROBIOL. 9 (2): 103 - 108

\title{
THE PREVALENT BACTERIAL ISOLATES OF DENTAL CARIES IN SCHOOL AGE CHILDREN ATTENDING THE DENTAL CLINIC OF OAUTHC, ILE-IFE
}

\author{
* ${ }_{1}$ Hassan-Olajokun, R. E., ${ }_{2}$ Folarin A. A., ${ }_{3}$ Olaniran O., 4 Umo A. N. \\ ${ }^{1,3}$ Department of Medical Microbiology and Parasitology College Of Health Sciences \\ Obafemi Awolowo University, Ile-Ife. and \\ ${ }^{2}$ The School of Medical Laboratory Sciences Obafemi Awolowo \\ University Teaching Hospital Complex, Ile-Ife.
}

*Corresponding Author E-mail: racheloghogho @yahoo.co.uk Tel: +2348034037587

\begin{abstract}
The study was conducted at the dental clinic of Obafemi Awolowo University Teaching Hospital Complex, IleIfe. A total of $\mathbf{1 0 0}$ carious samples were collected from children of varying age and sexes. The bacteria isolated were $S$. mutans: $45.6 \%$, Lactobacillus spp: $41.2 \%$ and $S$. aureus: $13.2 \%$. Out of the 100 samples, 88(5) had mixed growth of bacteria and the common bacteria combinations were $S$. mutans and Lactobacillus spp.(43.2\%), S. mutans and.S. aureus $(\mathbf{3 8 . 6 \% )}$ ) and Lactocillus spp and $S$. aureus (18.2\%)The distribution pattern of dental caries in relation to gender showed a higher frequency in females than males with the initiator $S$. mutans having $565.8 \%$ in female and $44.2 \%$ in males. The organisms appear to be more prevalent in children of 6-10 years considering the initiator $S$. mutans being $73.1 \%$ while ages $1-5$ years were least affected with $5.8 \%$. prevalence. Pefloxacin, Chloramphenicol, Ceftriaxone and Ciprofloxacin are most effective against the caries-inducing organisms with an average susceptibility range of $76.1 \%$ to $92.2 \%$.
\end{abstract}

\section{INTRODUCTION}

Dental caries is one of the most common disorders in the world, second only to common cold. It is the most important cause of tooth loss in younger people due to high dependence on dietary sucrose and frequency of eating, ${ }_{1}$ Caries is a disintegration of the teeth beginning at the surface and progressing inwards.

Caries is not caused by a single organisms, rather it results from the damage caused by complex micro-organisms. There is however a central role for S. mutans in the initiation of dental caries. S. mutans, Lactobacilli and Antinomycetes have been reported to play a role in the pathogenesis of dental caries.2 Gabris et $\mathrm{al}_{2}$ indicated that coronal caries is largely a disease of children with steady increase until 15 years of age and then diminishes in early children. Root caries as earlier reported by Hilson $_{3}$ particularly affect the proximal surfaces of the cheek teeth and is primarily a disease of older adult. The pattern of dental caries is similar in members of the same family over several generations. Environmental factors such as diet and oral hygiene habits play a large role in causing dental caries. The development of dental caries also depends on genetic, hormonal, notional and many other factor $_{4}$ the clearest singly factor in caries epidemiology still remain sugar. In the recent times, there has been so much discussion and emphasis on the issue of dental caries increase in the developing countries vis a vis the rate of sugar consumption in these countries. The study was therefore undertaken to example the bacteria etiology and their 
antigiogram in children as well as the current prevalence rate of the infection for which there is no recent report in this environment.

\section{MATERIALS AND METHODS STUDY DESIGN}

All patients (children) that had visible carious on their teeth attending the Dental clinic of Obafemi Awolowo University Teaching Hospital Complex (OAUTHC). Ile-Ife, Osun State, Nigeria between March 2004 and February 2005 were studied and swabs were obtained. The study included the documentation of age and sex of the subjects.

\section{SAMPLE COLLECTION AND PROCESSING}

A total of one hundred samples were obtained from 100 subjects who had not commenced treatment as at the time of c collection of samples. The control samples were collected from apparently normal healthy children with no history of dental carries. Samples were transported immediately to the laboratory for processing. For the bacteriological processing, Chocolate, Cystine Lactose Electrolyte Deficient (CLED) and MacConkey were employed. The Chocolate and CLED agar were incubated at 5$10 \% . \mathrm{CO}_{2}$ at $35-37 \% \mathrm{C}$ for 24 hours and the MaConkey aerobically at $35-37 \% \mathrm{C}$ for 24 hours. All isolates were characterized using the scheme of Chessbrough 5 and Cowan $_{6}$. Susceptibility to antimicrobial agents were done by the disk diffusion method using Diagnostic Sensitivity Testing (DST) agar as described by $\mathrm{NCCLS}_{7}$.

\section{RESULTS}

Bacteria were isolated from $100.0 \%$ of the subjects. The bacteria isolated were Streptococcus mutans. Lactobacillus spp and
Staphylococcus aureus, S. mutan had ghest frequency (45.6\%), Lactobacilllus spp (41.2\%) and S. aureus (13.2\%) as shown in table 1.

Table 2 revealed that specimens from $88.0 \%$ of the subjects had mixed growth of bacteria and the bacteria combinations were $S$. mutans and Lactobacillus spp (43.2\%).

S. mutans and S. auareus (38.6\%) and the least combination was Lactobacillus spp and $S$. aureus (18.2\%).

Table 3 shows the distribution pattern of dental caries in relation to gender and age indicating that it occurs more frequently in females than in males with the initiator $S$. mutans being $55 \%$ in female and $44.2 \%$ in males followed by Lactobacillus spp being $72.3 \%$ in females and $27.7 \%$ in males . S. aureus_occur more in female $(66.7 \%)$ than in males $(33.3 \%)$.

Distribution pattern of dental caries among the subjects in relation to age shows that the $\mathrm{S}$. disease is most prevalent among children of age 6-10years considering the initiator $S$. mutans having $73.1 \%$ while ages 1-5years are least affected as recorded in table 4 . In table 5 is presented the distribution of the organisms isolated from the control subjects giving $S$. albus $(70 \%)$ with males having higher frequency $(40 \%)$ and females (30\%). Klesiella spp gave a $30 \%$ made up of females $(20 \%)$ and males $(10 \%)$.

Table 6 shows the antibiotic susceptibility test of the isolates with pefloxacin chloramphenicol, ceftriaxone and Ciprofloxacin being most effective giving average susceptibility of $92.9 \%$, $81.8 \%, 78.6 \%$ and $76.1 \%$ respectively. Also shown in table 6 is the susceptibility pattern of the isolates from control sample to some antibiotics. 
TABLE I: Frequency of distribution of the organisms implicated

$\begin{array}{lcc}\text { Organisms } & \text { Frequency } & \text { Percentage Frequency (\%) } \\ \text { S. mutans } & 52 & 45.6 \\ \text { Lactobacillus spp } & 47 & 41.2 \\ \text { S. aureus } & \underline{15} & 13.2 \\ \text { TOTAL } & \underline{114} & 100.0\end{array}$

TABLE 2: Frequency of bacterial combination in mixed culture obtained from dental caries

\begin{tabular}{lcr}
\hline Organisms & Frequency & Percentage F \\
\hline S. mutans and Lactobacillus spp & 38 & 43.2 \\
S. mutans and S aureus & 34 & 38.6 \\
Lactobacillus and S. aureus & 16 & 18.2
\end{tabular}

TABLE 3: Distribution according to sex in percentage

\begin{tabular}{llc}
\hline & Male & Female \\
\hline Isolated Organism & $\mathrm{N}(\%)$ & $\mathrm{N}(\%)$ \\
S. mutans & $23(44.2)$ & $29(55.8)$ \\
Lactobacillus spp & $13(27.7)$ & $34(72.3)$ \\
S. aureus & $5(33.3)$ & $10(66.7)$
\end{tabular}

TABLE 4: Distribution according to age in percentage

\begin{tabular}{llll}
\hline Isolated Organism & $\mathbf{1 - 5 y e a r s}$ & $\mathbf{6 - 1 0 y e a r s}$ & $\mathbf{1 1 - 1 5 y e a r s}$ \\
\hline & $\mathrm{N}(\%)$ & $\mathrm{N}(\%)$ & $\mathrm{N}(\%)$ \\
S. mutans & $3(5.8)$ & $38(73.1)$ & $11(21.1)$ \\
Lactobacillus spp & $3(6.4)$ & $3(6.4)$ & $41(87.2) 0$ \\
S. aureus & $4(26.0)$ & $6(41.0)$ & $5(33.3)$
\end{tabular}

TABLE 5: Distribution according to sex in percentage of the control

$\begin{array}{lll}\text { Isolated Organism } & \text { Male } & \text { Female } \\ & \mathrm{N}(\%) & \mathrm{N}(\%) \\ \text { S. albus } & 4(40.0) & 3(30.0) \\ \text { Klebsiella spp } & 1(19) & 2(20.0)\end{array}$


TABLE 6: Susceptibility Pattern of the Isolates from dental caries and from control to Some antibiotics

\begin{tabular}{llllll} 
& S. mutans & \multicolumn{2}{c}{ Lactobacillus sp S. aureus } & Klebsiella & S. albus \\
No. of isolates & 52 & 47 & 15 & & \\
Antibiotics & $\mathrm{N}(\%)$ & $\mathrm{N}(10.00)$ & $\mathrm{N}(\%)$ & & \\
Augmentin & $48(92.30)$ & $5(10.60)$ & $7(46.70)$ & 100.00 & 0.00 \\
Amoxacillin & $0(0.00)$ & $5(10.60)$ & $2(13.30)$ & 0.00 & 0.00 \\
Chloramphenicol & $52(100.00)$ & $47(100.00)$ & $10(66.70)$ & 100.00 & 100.00 \\
Ceftriaxonne & $42(80.70)$ & $44(93.60)$ & $15(100.00)$ & 100.00 & 100.00 \\
Co-Trimoxazole & $25(80.10)$ & $0(0.00)$ & $5(33.30)$ & 0.00 & 0.00 \\
Ciprofloxacin & $32(61.50)$ & $30(63.80)$ & $12(80.00)$ & 100.00 & 100.00 \\
Fortum & $0(0.00)$ & $0(0.00)$ & $0(0.00)$ & 100.00 & 100.00 \\
Erythromycin & $0(0.00)$ & $40(84.10)$ & $6(40.00)$ & 0.00 & 100.00 \\
Gentamycin & $20(38.50)$ & $0(0.00)$ & $13(86.70)$ & 100.00 & 100.00 \\
Tetracyclin & $0(0.00)$ & $26(55.30)$ & $6(40.00)$ & 100.00 & 100.00 \\
Pefloxacin & $52(100.00)$ & $40(85.70)$ & $12(86.70$ & 100.00 & 100.00
\end{tabular}

\section{DISCUSSION AND RECOMMENDATIONS}

The results obtained showed that children are affected by dental caries as they advanced in age, and this is in line with the reports of Gabris 2 et al emphasizing that the frequency of dental caries increases steadily until 15years or so and then diminishes in early adulthood. Streptococcus mutans appear as the most common organism associated with dental caries and closely followed by Lactobacillus spp as revealed in table 1 . This high percentage of $S$. mutan supports previous reports of some researchers $_{(8,9)}$ that the initiation and progression of dental caries is closely associated with $S$. mutans. It can therefore be inferred S. mutans play an important role in the aetiology of caries in human.

In the present study, Lactobacillus was not found in non-caries teeth but seen with a lower percentage in carious teeth compared to $S$. mutans. This suggest that Lactobacillus probably plays a role in the initiation of caries and their presence in caries lesions may be an indication of their involvement in the progression of such lesions. This can be buttressed by the highest frequency of mixed culture of S. mutans and Lactobacillus spp as revealed in table 2 . Relatively small number of $S$. aureus were isolated from the carious teeth but not in non-carious teeth. The emergence of $S$. aureus in the caries lesions can be attributed to the facultative habit of $S$. aureus.

In this study Hilsons 3 report that dental caries appear to be more common in girls than boys. The high frequency of Lactobacillus spp in females recorded further confirms his work that the early eruption of teeth in females provides the anaerobic state for Lactobacillus to thrive. This result is also in conformity with the work done by Seibert ${ }_{10}$ et al while investigating the $\mathrm{S}$. mutans level and caries prevalence in lowincome school children $47 \%$ of the children with caries had high S. mutan level, females had S. mutans level than males in the 9-13years group. Analysis of variance test indicates that the level for older females (9-13years) were significantly 
higher than those observed in males in the same age group. Staphylococcus albus and Klebsiella spp were isolated from the control children. The presence of Klebsiella support the work of Gerald $_{11}$ et al that Gram negative rods are isolated from the mouth and that diet has a marked influence on the relative composition of mouth flora.

The antibiograms of the micro-organisms isolated (table 6) indicate a wide range of sensitivity to different antibiotics with Ceftriaxone, Pefloxacin and Chloramphenicol having the highest sensitivity patter. It therefore seems that the use of these drugs may reduce e the incidenc e and severity of caries in individual and communities. However, first line drugs for S. mutans as recommended by Tierny and colleagues $_{12}$ include Penic illin and/or Gentamycin. In this work S. mutans has not shown high sensitivity of Gentamycin (38.50\%) nor to Amoxicillin which represent the Penic illins. It could be inferred that resistance strains of S. mutans are emerging and this reqire further studies. Further studies are also necessary to access the level of protection against dental caries offered by the use of these antibiotics.

\section{RECOMMENDATIONS}

As dental caries is reappearing in many countries as public health crisis, the following steps can be taken to curtail the disease:-

\section{Information:-}

The passage information in health system is the basis of health education and therefore efforts should be intensified on oral health education in schools as this will interrupt the currently progressing rate of dental caries among children. The general public should be well informed about the importance of good oral hygiene.
Pregnant women and nursing mothers should be educated on the mode of transmission of normal flora from their mouth to their children.

Chewing sticks for tooth cleaning should be encouraged as they have been shown to have inhibitory effect $\mathrm{t}$ on microbial flora causing dental caries. Import of foreign method of tooth cleaning should not be overemphasized.

\section{Diet:-}

While emphasizing sugar in the case of dental caries development, the role of balanced diet in the maintenance of good health cannot be over looked. The rate of consumption of sugar can be reduced by restricting to the meal times since it is impossible and quite impracticable to totally stop the consumption of sugar. Calcium in diet has the potentials of building stronger teeth.

\section{Fluorides:-}

The government at every level should strongly consider fluoridation of public drinking water as a worthwhile project. In addition to the present effort to ensure that bottled and sachet water are portable for drinking, NAFDAC (National Agencies of Food and Drugs Administration and Control) should also insist that such water have adequate content of fluoride ions. Fluoride levels in main food items should be determined and made known to the public. This calls for urgent need for fluoride level research in every country. All tooth pastes lacking fluoride or insufficient fluoride level should be banned from the market.

\section{Fissure sealing:-}

Clinical experience has shown that some children are at high risk of caries attack. In such children, prophylactic administration of fissure sealing should be provided as soon as the teeth pit and fissure erupt into the mouth.

\section{Dental check-up:-}


A periodic dental check-up at least twice a year for growing children should be encouraged. Dentists should endeavour to visit schools (Nursery, Primary and Secondary) for check-ups on growing children.

\section{Microbial Monitoring:-}

As science is dynamic, the periodic monitoring of the oral microbial flora and their drug sensitivity pattern should be carried out and necessary information passed to the public. Dental caries, though a disease of great antiquity is not a disease of the past since it is reappearing in many countries as a public health crisis. It is therefore important that the public health be taught on prevention, early recognition (visible white spot on the tooth with excruciating pain) and reporting to dental clinic for proper prognosis. This underscores the need for laboratory diagnosis, confirmation of dental caries and the antibiograms of incriminating micro-organisms for proper management of patients and to reduce the development of resistant strains or multiple resistance to antibiotics.

\section{REFERENCES}

1. Graham Mount and Rory Hume: UCLA School Of Dentistry (2000)

2. Gabries, K; Nyarasdy, I; and Banoczy, J.: Significance of assassing risk factors for caries and their prevention: Orvosi hetilap 2002: 143 (24) 146-73

3. Hilson, S.: Dental Anthropology, New York; Cambridge University Press (1996)

4. Macowiak, P.: The normal microbial floral N. Engl. Jnl of Medicine : 1982;307:83

5. Cheesbrough, M.: Manual For Medical Laboratory Technology For Tropical
Countries Vol. 11, Microbiology University Press Cambridge (1984)

6. Cowan, S. T.: Manual For The Identification Of Medical Bacteria, Cambridge University Press(1985)

7. National Committee For Clinical Laboratory Standards(NCCLS) Performance Standard for antimicrobial disk susceptibility test approved standard $\mathrm{M}^{2} \quad \mathrm{~A}^{\mathrm{A}} \quad 5^{\text {th }} \quad$ Edition. Villanova P. a. NACCL, American Society Of Microbiology, Washington D. C. (1993)

8. Kingman, A. and Little, W.: Salivary Levels of Streptococcus mutans and Lactobacilli dental caries experiences in a US adolescent Population, Community Dent. Oral Epidemiol. 1984: 16: 98103.

9. Adetunji O. F; Akinshipe, B. O; Ogunbodede, E. O. and Ijaware, C. O. Bacteriological Studies of Dental Caries in Ile-Ife, Nigeria. Central Africa J. of Medicine 1985: 2:8

10. Seibert, W.; Farmer, D.C; Bolden, T. and Stewart, J. H.: Streptococcus mutans levels and caries prevalence in low-income school children. $J$. of the Tennessee Dental Ass : 2002: 82(1): 19-22.

11. Gerald, L; Mandell, J. E; Bennett and Raphael Dolin. Principle $s$ and Infectious Disease, $5^{\text {th }}$ edition: 1986: 2 , 689-691.

12. Tierney, L. M.Jnr; Mcphee, S. J. and Paradakis, M. A. Current Medical Diagnosis and Treatment, Appleton and Lange(1997). 